\title{
REAÇÃO AO IMPLANTE SUBCUTÂNEO DE PULPDENT EM RATOS
}

\section{"REACTION OF SUBCUTANEOUS CONNETIVE TISSUE OF RATS TO IMPLANTED PULPDENT"}

\author{
Liliane Yurgel de Oliveira * \\ Jesé Antônio F. Prieg ** \\ Jorge G iberto $C$. do Valle ***
}

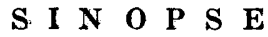

Com o propósito de estudar as reações provocadas no tecido conjuntiro, um tipo de Hidróxido de Cálcio - o Pulpdent - foi introduzido no dorso de 14 ratos albinos (Wistar), de um mês de idade no início da experiência.

Os animais foram sacrificados em intervalos de tempo que variaram de 1 a 5 mêses.

Da análise dos nossos resultados pede-se sugerir que o Pulpdent é relativamente bem aceito pelo organismo.

\section{N T R O D U C $\tilde{A}$ O}

Já cm 1953, por um trabalho de Dixon e Rickett (5), evidenciou-se a preocupação dos investigadores em testar o efeito biológico causado, no tecido mole, pelos materiais restauradores, sem, no entanto, serem adicionados os danos físicos causados leio preparo cavitário.

o Hidróxido de Cálcio é um mate- rial usado para capeamento da polpa de um dente, inadvertidamente exposta durante uma operação dental; é muitas vezes usada, portanto, em íntimo contato com o tecido pulpar.

A composição desses produtos varia: alguns são meramente suspenções en á áua destilada e outros têm, como solvente, Metil Celulose Aquosa. (11)

O produto que nós utilizamos tem, como solvente, Metil Celulose. Parece que uma solução aquosa de Metil CeIulose é o veículo de escolha no qual o Hidróxïdo de Cálcio deva ser incorporado, poïs a pasta assim formada possuiria todas as propriedades desejáveis num Hidróxido de Cálcio sem nenhuma das desvantagens costumeiramente encontradas em seu uso. (2)

Usando uma pasta, constituida de uma mistura de Hidróxido de Cálcio com $1 \%$ de uma solução de $\mathbf{M e -}$ ti] Celulose, como material de capeamento, Klein (6), em 1861, provocor, radiogràficamente demonstrável, a formação de uma dentina esclerosada

- Bobsta Conseno Nacional de Pesquisas, na Dtsciplina de Patologia, do Departamento de Odontologia Conservadora, Faeuldade de Odontologia, UFRGS.

- Prof. Assistente da Disctplina de Dentística Operatórta, do Departamento de Ountolo Conservadora, Faculdade de Odontologia, UFRGs.

*** Bolsista do Conselho de Pesquisa da Universidade Federal do Rio Grande do Sul, ne Diseip Ha de Patologia, do Departamento de Odontologia Conservadora, Faevidade de Odontologia, UFRGS.

O prestente trabalho fot realizado sob a orientação do Prof. Dr. HARDY BELING, Prof. Titular da Disciplina de Patologia, do Departamento de Odontologia Conservadoran Faculdade de Odontologia, UFRGE. 
logo abaixo do material, em $93 \%$ de 191 dentes decíduos.

O propósito deste trabalho foi estudar as reações do tecido conjuntivo à um tipo de Hidróxido de Cúicio - o PULPDENT.

\section{MATERIAIS E MéTODOS}

Para avaliar as qualidades irritacionais do Pulpdent, utilizamos a técnica de implante de material nc tecido conjuntivo, proposta por Mit. chell e Amos (9).

Com o Fulpdent foram confeccionados corpos de prova de $6 \mathrm{~mm}$ a $1 \mathrm{~cm}$. Como este material é uma pasta, os corpos de prova eram confeccionados cinco minutos antes de introduzí-los no dorso dos ratos, pois é o tempo requerido para a presa do material.

Foram utilizados 14 (quatcrze) ratos albinos (Wistar), com 1 mês de idade, no início da sxperiência, divididos em três grupos. 0 Grupo A consistia de 4 ratos e foram sa crificados 1 mês após o implante. 0 Grupo B consistia de 4 ratos, e foram sacrificados 2 meses após o implante.

O grupo $\mathrm{C}$ consistia de 6 ratos e foram sacrificados 4 e 5 meses após o implante do material.

$\mathrm{Na}$ necrópsia foi retirado para $\epsilon$ xame, mais ou menos $2 \mathrm{~cm}$ de pele e tecido conjuntivo da zona do implante, inclusive o material implantado. As peças foram fixadas $\mathrm{cm}$ Formol a $10 \%$, embebidas em parafina, seccionadas e coradas pela $\mathrm{He}-$ matoxilina e Eosina, e estudadas microscopicamente.

* PULPDENT - Rower Dent/MFG, Co/USA.

\section{R E S U L T A D O S}

O contanto do material sobre os tecidos causa uma fina camada de necrose. A seguir esboça-se uma cápsula, com os fibroblastos orientados paralelamente ao material com três on quatro camadas dé células, morfologicamente assemelhando-se ao periósteo. Fig. 1).

Seguem-se camadas estratificadas de vasos, na maioria paralelos à cápsula, entre os quais percebe-se célulás inflamatórias crônicas e formação de osso heterotópica. Fig. 2).

Zonas de hemorragia discreta são comuns, bem como a presença de pigmento hemático. Alguns vasos apresentam mineralização e outros tem sua parede tão espessada que se apresentam praticamente ocluidos.

A mineralização com formação de camadas periféricas de tecido ósseo imaturo, é melhor vista quando pequenos fragmentos do material se destacam da massa principal, dando uma figura mais simples.

A presença de células gigantes tipo corpo estranho é pequena e aparece, em geral, tentando circunscrever fragmentos de tecido osteóide. (Fig. 3).

Após 2 meses o material está completamente envolvido por uma massa fibrosa. Nas zonas aonde há falha de material, há uma proliferação abundante de células e vasos no tecido conjuntivo de tal modo que a "cavidade" cheia de material, única no início, aos poucos vai se transformando em várias "cavidades" menores pelo aparecimento de septos. (Fig. 4)

R. Fac. Odont. P. A.

15/16/17: 17-22, 1974/75/76 
A medida que o processo envelhece o tecido de granulação que recobre o material torna-se mais fibroso, : menos celular e menos vascularizado.

\section{DISCUS $\tilde{A} O$}

Os resultados encontrados por nós estão relativamente de acôrdo com os encontrados por outros investigadores, tanto os que estudaram o efeito do Hidróxido de Cálcio no tecido conjuntivo de animais de experimentação (9) (8), quanto os que estudaram seu efeito na polpa (2) (10) (6) (4) (1) (7).

Assim, a formação de uma mínima inflamação crônica, fibroplasia e formação de osso heterotópica, como resultado de implante de Hdiróxido de Cálcio no tecido conjuntivo, já havia sido observado por Mitchell e Amos (9) e Mitchell (8). Mesmo aumentando o intervalo de tempo entre o implante e o sacrifício dos animais havia sempre a presença de uma inflamação moderada e tecido osteóide associado à células gigantes. (8).

Os nossos achados em muito se relacionam aos observados por Nyborg (10), quando estudou os efeitos de Hidróxido de Cálcio na polpa de humano e de animais. Ele observou na superfície da polpa, ou seja, em contato com o material, uma camada de necrose, a seguir uma camada de fibras argirófilas e depois um tecido duro imaturo. Contra este tecido era depositada uma substância dentinói- de. É interessante a relação entre o depósito dessa "ponte" sobre a polpa expostá, tratada com Hidróxido de Cálcio, e a produção de tecido osteóide no conjuntivo.

Essas mesmas zonas foram confirmadas por Clarck (4), que sugeriu que o Hidróxido de Cálcio fosse um irritante não suficientemente forte como para necrosar a polpa mas sim que agiria como um estímulo para formação de uma ponte dentinária.

Também Macheti e Toledo (7) demonstraram, através da fluorescência da tetraciclina, que, pelo capeamento com Hidróxido de Cálcio, havia a formação de uma "mineralização secundária intratubular".

\section{O N C L U S Õ E S}

Observou-se a formação de uma pequena camada de necrose, seguida de fina cápsula fibrosa, vasos dilatados, pigmento hemático e células inflamatórias. A medida que o processo envelhecia o tecido de granulação ia se tornando mais fibroso, menos celular e menos vascularizadc. Observou-se, também, a presença: de pequenas áreas mineralizadas e de tecido osteóide em graus variados de maturação.

A pequena zona de necrose, o pequeno grau de infiltração celular e os estágios avançados, em que a reação se torna cada vez mais fibrosai, levam a crer que o material é bem tolerado pelo organismo, quando em contato com o tecido conjuntivo. 


\section{S Y N O P S I S}

A type of calcyum hidroxide PULPDENT - was implanted in the subcutaneous connetive tissue of fourteen rats one month old.

The tissue around the pellets were studied mycroscopically, after periods that ranged from one to five months.

It seems, from the observations that Pulpdent is relatively weel tolerated by the organism.
Gostaríamos de registrar nossos agradecimentos a Prof. ,Dr. Hardy Ebling, que, além de orientador des- te trabalho, participou ativamente na interpretação dos achados histológicos.

FIG. 1

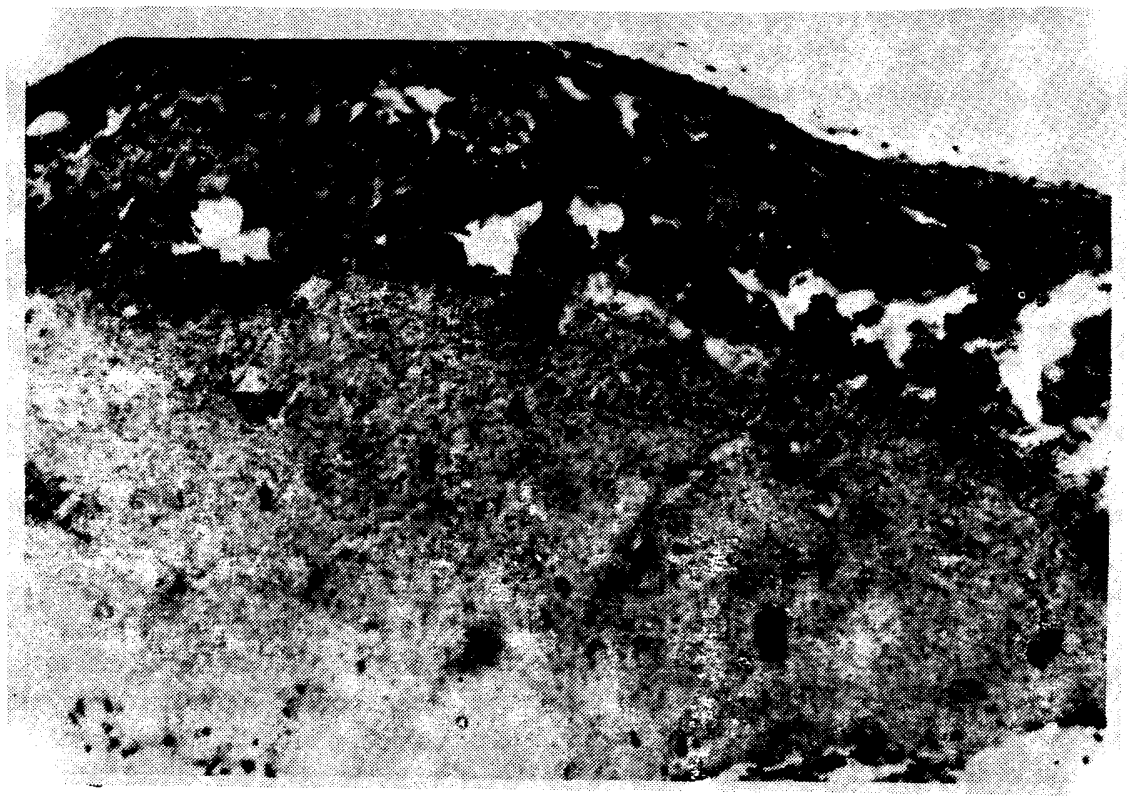

Pulpdent envolvido por capsula de tecido fibroso. Note a fina camada de necrose que se forma em contato com o material implantado, 2 meses após o implante. 


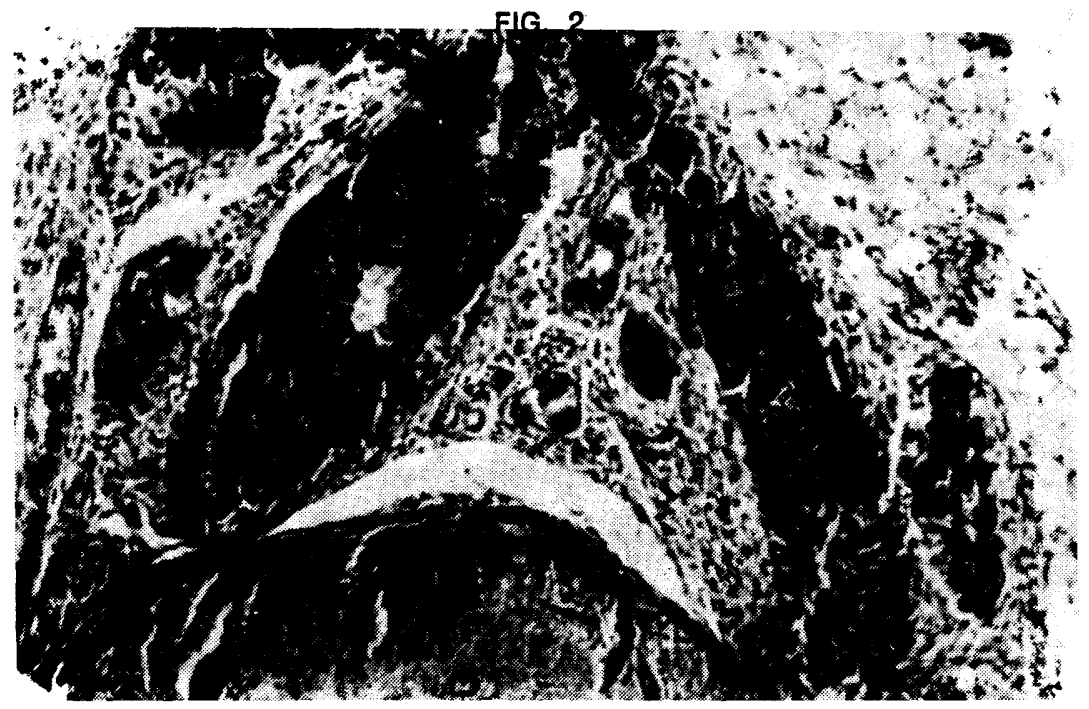

Formaça de áreas mineralizadas na capsula de tectdo conjuntivo fibroso, acom. panhada de grande numero de vasos e algumas celulas inflamatórias crónicas.

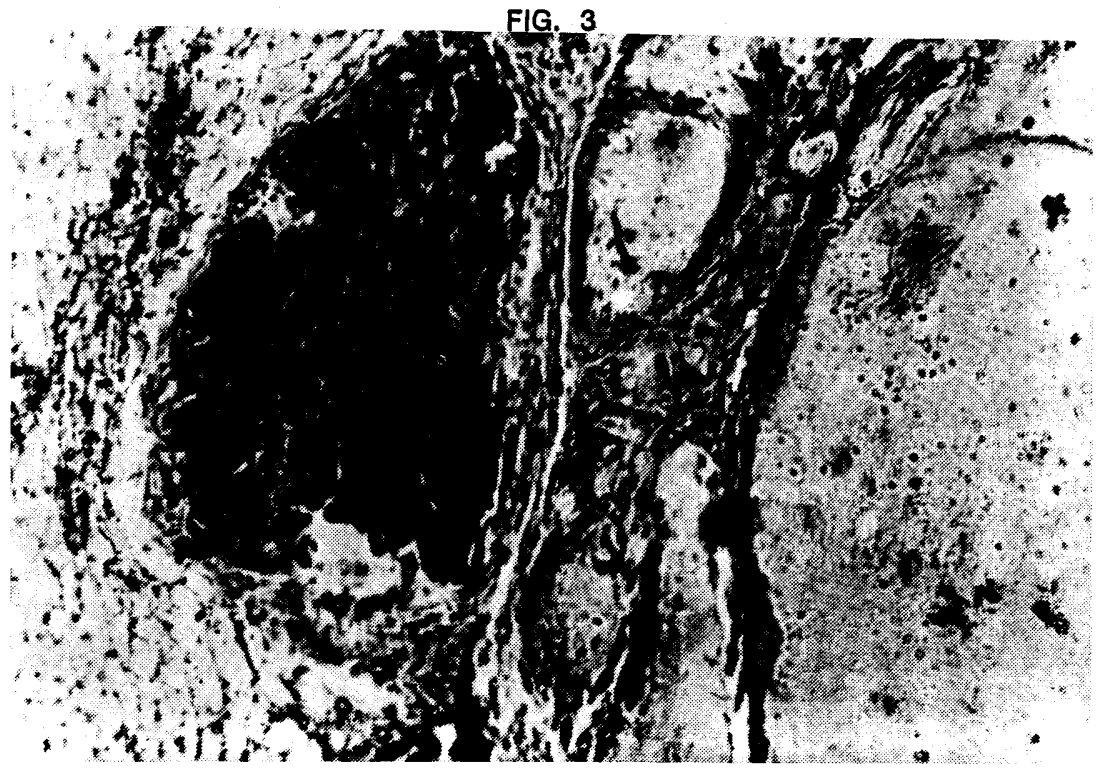

Pulpdent circundado por tecido conjuntivo fibroso e formaçăo de área mineralizada. Note a presença de célula gigante tentando englobar o tecido esteóide, 4 meses após o implante. 
FIG. 4

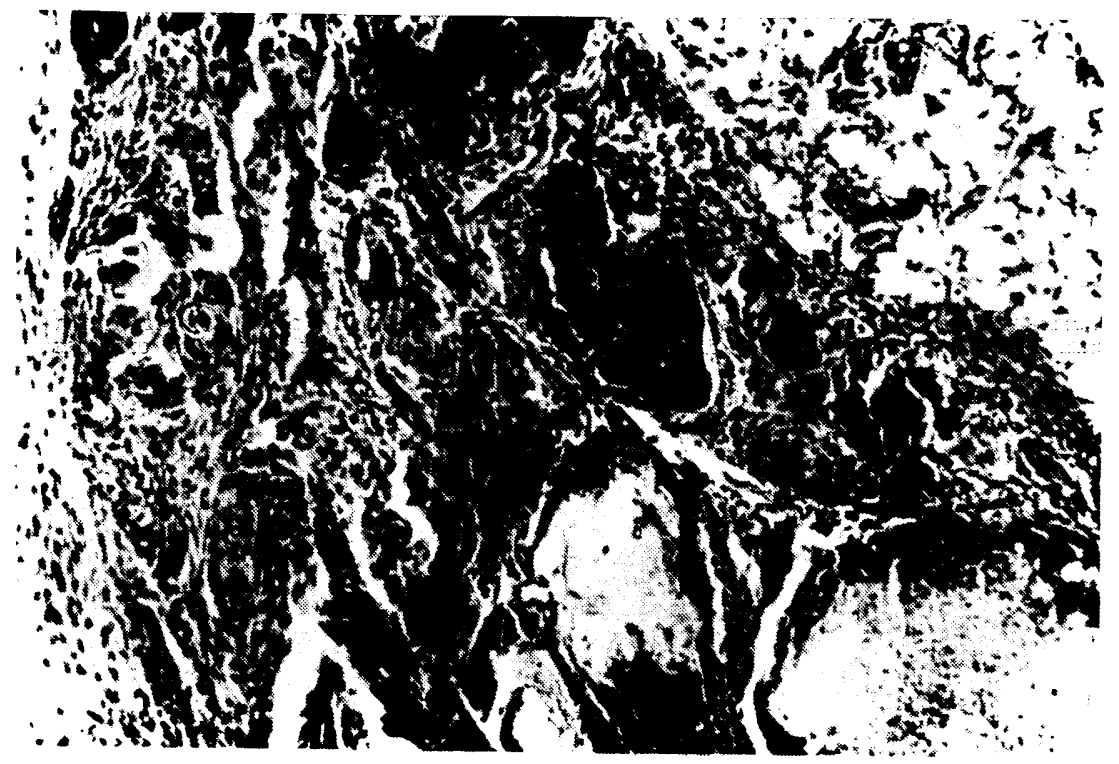

Tecido conjuntivo fibroso "dividindo" o material implantado como se fossem septos. Note as áreas mineralizadas na cápsula. 